\title{
'Nuvens negras' sob os céus claros e eugênicos na construção identitária da Canaã ou da pátria amada brasil
}

\section{'Black clouds' under clear and eugenic skies in the construction of the identity of Canaã or the beloved brazil}

\section{Marcos Teixeira de Souza* IUPERJ}

Resumo: O processo de construção da identidade nacional no Brasil envolve diversas questões, entre elas as supostas teorias raciais que circularam no Brasil no final do século XIX e início do século XX. Quanto a isto, é importante entender quais categorias e discursos moldam nossa realidade como nação e sentenciam determinados grupos a viverem à margem da história. O pensamento de Arthur de Gobineau e de Francis Galton, entre outros nomes, sobre raça como um ingrediente importante para o desenvolvimento social de uma nação influencia nossa intelectualidade. O romance Canaã (1902), escrito por Graça Aranha, ilustra bem este panorama ou parte dele.

Palavras-chave: Gobineau. Eugenia. Identidade nacional. Canaã.

\begin{abstract}
The process of the construction of national identity in Brazil involves several factors, including the racial theories which circulated in Brazil in the nineteenth century and the beginning of the twentieth century. In this respect, it is important to understand which categories and discourses have shaped the reality of Brazil as a nation and also condemn certain groups to live on the margins of history. The theories of Arthur de Gobineau and Francis Galton, among others, regarding race as an important ingredient in the social development of a nation influenced the Brazilian intelligentsia. The novel Canaã (1902) by Graça Aranha exemplifies this panorama.
\end{abstract}

Keywords: Gobineau. Eugenics. National identity. Canaã.
${ }^{*}$ Doutorando em Sociologia - Iuperj. Membro pesquisador do Centro de Estudos Afro-Asiáticos CEAA. E-mail: prof1marcos@ hotmail.com 
'Nuvens negras' sob os céus claros e eugênicos na construção identitária da Canaã ou da pátria amada brasil

\section{Introdução}

Muitos dos valores sociais, culturais e identitários do Brasil das últimas décadas do século XX e das primeiras décadas do século XXI foram construídos, postos e impostos em razão de acontecimentos no Brasil colonial, monárquico e recém-republicano. É recorrente assim, não sem sentido, olhar quais e como determinadas ideologias perpassaram o processo de formação da identidade nacional brasileira, ante certos dilemas e problemáticas do presente, revisitando esses períodos para entender as construções identitárias, e ler nas linhas e entrelinhas da História do Brasil os diversos rostos e contribuições que deram cores e culturas a esta nação.

Além do aspecto de retornar ao passado dos acontecimentos internos, deve-se contextualizar o Brasil no mundo, principalmente diante das nações influentes em sua formação identitária, e buscar as ideologias estrangeiras, de cunho social, político, cultural, étnico, que marcaram e marcam a nação brasileira. Neste sentido, o presente artigo pretende pontuar alguns aspectos do pensamento sobre raça no Brasil, tendo como pano de fundo o romance Canaã, de Graça Aranha, publicado em 1902.

Do estudo da formação da nossa dita identidade nacional emergem muitos temas e debates, não poucos conflitos abertos e silenciosos, os quais ora se calam, ora se avivam na sociedade em meio a buscas por resposta ou respostas consistentes para a problemática não só da identidade do que seja brasileiro, mas também do que não seja brasileiro. Sob este prisma, falar em identidade nacional envolve classificar e hierarquizar comportamentos, falas, expressões culturais, etc., que se julgam pertencentes a nós, em detrimento do dito outro. Tendo como pano de fundo uma discussão sobre como as nações foram construindo suas respectivas identidades, bem como os indivíduos estão conformes a essas construções, Stuart Hall (2006), em A identidade cultural na pós-modernidade, afirma que:

[...] as identidades nacionais não são coisas com as quais nós nascemos, mas são formadas e transformadas no interior da representação. Nós só sabemos o que significa ser "inglês" devido ao modo como a "inglesidade" (Englishness) veio a ser representada - como um conjunto de significados - pela cultura nacional inglesa. Segue-se que a nação não é apenas uma entidade política, mas algo que produz sentidos - um sistema de representação cultural. (HALL, 2006, p. 49).

Hall assim elabora a tese de que a identidade não é algo estático, fixo, imutável. Ao contrário, tem-se um processo permanente de construção e reconstrução da identidade, sendo a cultura um elemento muito presente. Partindo desta posição de Hall (2006), em torno da chamada identidade nacional que se engendra nos indivíduos e nas sociedades como portadora de um conjunto de significados, e não inata, algumas perguntas, 
olhando para o Brasil, fazem-se oportunas: o que nos faz brasileiro? O que nos identifica como brasileiro? Quem é o brasileiro?

Responder ou discutir tais perguntas tem sido o objeto de estudo de muitos sociólogos, antropólogos, entre outros especialistas das ciências sociais e humanas, principalmente a partir do século XIX. Manuel Bonfim, Darcy Ribeiro, Sérgio Buarque de Holanda, Gilberto Freyre, Roberto DaMatta, entre tantos outros, tentaram elucidar ou, pelo menos, descrever alguns dos rostos deste Brasil diverso. Na obra Cultura brasileira e identidade nacional (1985), Renato Ortiz diz: “O tema da cultura brasileira e da identidade nacional é um antigo debate que se trava no Brasil. No entanto, ele permanece atual até hoje, constituindo uma espécie de subsolo estrutural que alimenta toda discussão em torno do que é nacional.” (ORTIZ, 1985, p. 7).

Este subsolo estrutural que Ortiz menciona se deu em torno de diversos debates intelectuais de autores como Sílvio Romero, Nina Rodrigues, entre outros pensadores, cujos olhares se voltaram para as temáticas de meio, raça, miscigenação, embranquecimento, etc. Este antigo debate a que alude atravessa nossa literatura, e tal pode ser vista como um instrumento importante para entender como nossa identidade foi e é forjada em meio ao escravismo, à imigração, aos projetos de poder, etc. Recepções e tratamentos diferenciados em relação aos negros, aos europeus e aos indígenas, entre outros grupos, legaram muitos reflexos na construção da identidade nacional.

Muitos interesses socioeconômicos e ideológicos fomentaram teorias raciais do que era bom ou ruim para a sociedade brasileira, do que era aceito ou rejeitado, sobretudo nas duas últimas décadas do século XIX e nas primeiras do século XX. Para compreender essas teorias raciais e suas dinâmicas sociais e políticas na sociedade brasileira, convém, antes, identificar alguns dos principais acontecimentos e ideologias raciais, entre a segunda metade do século XIX e primeiras décadas do século XX, emergentes em outros países e influentes no pensamento racial, político e intelectual no Brasil.

\section{Gobinismo e eugenismo: marcas influentes no pensamento racial brasileiro}

A máxima de que o brasileiro tem mania de imitar o que outras nações fazem pode não proceder em todos os casos, mas no que se refere à questão racial, pelo menos num momento, teve essa máxima como fato: a importação de teorias raciais.

Dentre talvez os precursores estrangeiros de teorias raciais junto à elite política e intelectual brasileira, Joseph Arthur Gobineau (1816-1882), mais conhecido como Conde Gobineau, com sua obra Essai sur l'inégalité 
'Nuvens negras' sob os céus claros e eugênicos na construção identitária da Canaã ou da pátria amada brasil

des races humaines (Ensaio sobre a desigualdade das raças humanas, 1855), assumiu um papel marcante na propagação da tese da superioridade da $r a c ̧ a^{1}$ branca sobre as demais raças, em especial a negra.

Com Gobineau, a elite brasileira, majoritariamente branca, encontrou um suporte científico para se sobrepor aos negros da pré e pós-abolição, legitimar e manter seu poder na sociedade brasileira, desdizendo na prática o sentimento de brancos e negros igualmente cidadãos, ainda que, no discurso, muitas vezes se pregasse o fortalecimento da nação com o fim da escravidão.

A influência de Gobineau não se deu no Brasil somente pela obra supracitada e teorização racista, mas também pela sua curta estada no Brasil, na função de diplomata, e pela amizade com D. Pedro II, com quem trocara correspondência.

Laura Moutinho (2004), na obra Razão, “cor” e desejo, ao mapear em seu segundo capítulo autores clássicos e influentes na historiografia brasileira, no tocante à racialidade, refere o breve período em que Gobineau morou no Brasil e a proximidade do diplomata com Dom Pedro II:

Esse autor, principal artífice das teses sobre a degenerescência da "mistura" entre "raças", viveu no Brasil por um ano e dois meses no final do século passado. Como pode ser depreendido da citação anteriormente, não simpatizou com os brasileiros - a quem chamava de malandros e degenerados - mas foi, no entanto, um grande amigo do Imperador Pedro II - um ariano legítimo que é igualmente inteligente e erudito, na visão do nobre francês. (MOUTINHO, 2004, p. 56).

Além das teorias racistas de Gobineau, veiculadas no Essai sur l'inégalite des races humaines, outra referência teórica estrangeira que marcou a elite intelectual e política do Brasil foi a de Francis Galton (1822-1911), cujo nome se tornou conhecido, não só no Brasil mas no mundo, pelo neologismo eugenia: "Galton definiu eugenia como o estudo dos agentes sob o controle social que podem melhorar ou empobrecer as qualidades raciais das futuras gerações seja física ou mentalmente.”2

Nas duas primeiras décadas do século XX, os ideários da eugenia se espalharam pelo mundo, idealizando uma suposta supremacia racial, a busca de um dito melhoramento racial, com o objetivo de desenvolvimento das nações. Acreditava-se que nações mais fortes eram formadas por seres, eugenicamente falando, mais aptos e fortes.

No romance Canaã (1902), de Graça Aranha, é narrada a chegada e o estabelecimento dos alemães (e/ou pomeranos, prussianos, etc.) no solo capixaba, sendo praticamente a única obra de reconhecimento literário em nível nacional que apresenta o estado do Espírito Santo como paisagem. Segundo as historiografias literárias de Bosi (2006) e de Carvalho (1953), entre outros, este romance de Graça Aranha é tido como pré-modernista, e
${ }^{1}$ Termo muito utilizado à época em detrimento de grupo étnico, etnia, entre outros. 
encena, além deste fluxo migratório para o Espírito Santo, grandes debates da época: discussões sobre raça, circulantes entre as últimas décadas do século XIX e o início do século XX, trazendo à tona fortemente uma dicotomia por meio de dois protagonistas do romance: os imigrantes Milkau e Lentz, cada qual com sua tese sobre o peso da questão racial na construção do Brasil.

Ao longo da narrativa, Milkau e Lentz vão duelar em palavras e argumentos para defender as respectivas teses sobre a questão racial no Brasil como fator de desenvolvimento ou não para a nação, a partir da imigração, da qual fazem parte. A sequência de falas a seguir ilustra bem este debate: - Mas isto é a lei da vida e o destino fatal deste País. Nós renovaremos a Nação, nos espalharemos sobre ela, a cobriremos com os nossos corpos brancos e a engrandeceremos para a eternidade. (ARANHA, 1982, p. 49). E em outra passagem:

- Ora - interrompeu Milkau -, tu sabes bem como se tem vencido aqui a Natureza, como o homem vai triunfando...

- Mas o que se tem feito é quase nada, e ainda assim é o esforço do europeu. O homem brasileiro não é fator do progresso: é um híbrido. E a civilização não se fará jamais nas raças inferiores. Vê, a história... (ARANHA, 1982, p. 52).

Como se constata nos fragmentos transcritos, o europeu, ou mais especificamente o homem branco, é posto como fator de desenvolvimento. Esta fala, considerada comum, exclui o negro como um dos construtores da nação. Em outra passagem, é apresentada sutilmente a distinção luz (brancura) e trevas (negrume):

Um dos erros dos intérpretes da História está no preconceito aristocrático com que concebem a ideia de raça. Ninguém, porém, até hoje soube definir a raça e ainda menos como se distinguem uma das outras; fazem-se sobre isto jogos de palavras, mas que são como estes desenhos de nuvens que ali vemos no alto, aparições fantásticas do nada... E, depois, qual é a raça privilegiada para que só ela seja o teatro e o agente da civilização? [...] O que vejo neste vasto panorama da História, para que me volto ansioso e interrogante, é a civilização, deslocando-se sem interrupção, indo de grupo a grupo, através de todas as raças, numa fatal apresentação gradual de grandes trechos da terra, à sua luz e calor...Uns se vão iluminando, enquanto outros descem às trevas... (ARANHA, 1982, p. 52).

O estabelecimento da existência de graduação de raças, basilar no pensamento eugênico, prevê o europeu como agente de desenvolvimento, em detrimento do africano (ou do negro), a quem se atribui pouca chance, a não ser na fusão com o branco.

LENTZ - Até agora não vejo probabilidade da raça negra atingir a civilização dos brancos. Jamais a África... MILKAU - O tempo da África chegará. 
'Nuvens negras' sob os céus claros e eugênicos na construção identitária da Canaã ou da pátria amada brasil

As raças civilizam-se pela fusão; é no encontro das raças adiantadas com as raças virgens, selvagens, que está o repouso conservador, o milagre do rejuvenescimento da civilização. O papel dos povos superiores é o instintivo impulso do desdobramento da cultura, transmitindo de corpo a corpo o produto dessa fusão que, passada a treva da gestação, leva mais longe o capital acumulado nas infinitas gerações.

[...] LENTZ - Não acredito que a fusão de espécies radicalmente incapazes resulte numa raça que se possa desenvolver a civilização. Será sempre uma cultura inferior, uma civilização de mulatos, eternos escravos em revoltas e quedas. (ARANHA, 1982, p. 52).

O debate entre Milkau e Lentz, que Graça Aranha encena neste romance, mostra uma extensa articulação de argumentos e contra-argumentos, os quais circundam o processo de formação da identidade nacional do Brasil entre as últimas décadas do século XIX e as primeiras décadas do século XX. Segundo Alfredo Bosi, em História concisa da literatura brasileira (2006):

Caberia ao romance de Lima Barreto e de Graça Aranha, ao largo ensaísmo social de Euclides, Alberto Torres, Oliveira Viana e Manuel Bonfim, e à vivência brasileira de Monteiro Lobato o papel histórico de mover as águas estagnadas da belle époque, revelando, antes dos modernistas, as tensões que sofria a vida nacional. (BOSI, 2006, p. 306).

De certo modo, estas temáticas postas por estes romancistas e ensaístas citados por Bosi situam-nos como uma das antessalas do eugenismo no Brasil. Em relação ao romance Canaã, de Graça Aranha, segundo Bosi (2006), este se deve à passagem de Graça Aranha pelas terras capixabas:

Acasos da fortuna levaram-no, jovem juiz municipal, a fixar-se por alguns meses em Porto Cachoeiro, pequena comunidade do Espírito Santo, onde predominavam imigrantes alemães. A observação da vida social, com seus patentes contrastes entre selva e cultura, trópico e mente germânica, era bem de molde a tentar um espírito propenso ao jogo de ideias e, ao mesmo tempo, sensível às formas e às vozes da paisagem. Assim nasceu Canaã, retrato de algumas teses em choque e deleitação romântico-naturalista das realidades vitais. A dualidade, não resolvida por um poderoso talento artístico, criou graves desiquilíbrios na estrutura da obra, cujo valor, enquanto romance, é ainda hoje posto em dúvida por mais de um crítico respeitável [...] documento literário precoce, nesse sentido, o romance, embora padeça de generalizações inerentes ao estilo imaginoso do autor, projeta com nitidez um problema fundamental do século XX brasileiro, antecipando-se de muito à tomada de consciência dos modernistas. (BOSI, 2006, p. 326).

Ao longo do século XX, este problema fundamental teria um dos seus pilares no eugenismo. A criação das sociedades eugênicas em várias partes do mundo, inclusive no Brasil, cuja primeira foi a Sociedade Eugênica de 
São Paulo, fundada em 1918, e de congressos nacionais e internacionais, espraiaram o mar nefasto do racismo sobre as etnias indígenas e negras. Surge então, neste contexto amparado por teorias racistas - as de Gobineau e de Glaton, entre outros pensadores europeus -, a concepção de que a matriz branca era sinônimo de força, de saúde, de inteligência, de aptidão para a formação de uma identidade nacional de um Brasil forte. Assim, concebe-se a ideia de embranquecer a população brasileira. Com Canaã, publicado em 1902, de certa forma Graça Aranha antevê um cenário eugênico, e seu romance tem o perfil de uma obra que se situa entre a Abolição e as diversas discussões em torno da raça levadas a efeito pela intelectualidade.

A abolição e a pós-abolição tornaram-se não só um problema político mas também uma dificuldade de percepção. Era difícil perceber o negro, secularmente visto e tido como mercadoria, agora como um cidadão ou um potencial cidadão, numa próxima ou igualitária hierarquia social em relação aos brancos. Neste contexto, a elite intelectual brasileira do fim do século XIX e começo do século XX, em geral, viu com bons olhos as teorias eugênicas e raciais ligadas à supremacia racial dos brancos sobre as demais raças.

A questão racial tal como foi colocada pelos precursores das Ciências Sociais no Brasil adquire na verdade um contorno claramente racista, mas aponta, para além desta constatação, um elemento que me parece significativo e constante na história da cultura brasileira: a problemática da identidade nacional. (ORTIZ, 1985, p. 13).

No olhar de grande parcela da elite intelectual brasileira, a Abolição significou uma ameaça, um momento de desassossego, ante um cenário de pós-abolição que permitisse um caminho de igualdade de oportunidades entre negros e brancos, tendo em vista que as teorias raciais vigentes preconizavam uma população branca como ideal de desenvolvimento, e não mulata ou negra. Assim, nessa época, a introdução de mecanismos impeditivos de ascensão ao negro na participação política foi uma das preocupações das elites políticas e intelectuais, entre as quais muitos médicos, antropólogos e juristas.

Pautadas principalmente pela ideologia gobiniana e eugênica, temerosas com os rumos da nação brasileira, o que pode ser entendido também como a construção de uma identidade nacional futura do Brasil, essas elites propagaram várias pesquisas ditas científicas sobre a suposta inferioridade do negro e sua inserção na sociedade brasileira.

Por outro lado, no ardor da formação de uma nação forte e diante do medo de uma suposta inferiorização da nação com a Abolição, as elites intelectuais viram nas tentativas de embranquecer ou, ao menos, miscigenar a população brasileira com vistas ao seu aclaramento gradativo, saídas 
'Nuvens negras' sob os céus claros e eugênicos na construção identitária da Canaã ou da pátria amada brasil

viáveis. Sobre isto, Olívia Maria Gomes da Cunha (2002), em sua extensa obra Intenção e gesto. Pessoa, cor e a produção da (in)diferença no Rio de Janeiro, 1927-1942, disserta que a eugenia esteve em voga na sociedade como um projeto contemporâneo e moderno:

Ao abordar as discussões a respeito de definições distintas acerca da formação social brasileira, diferentes 'eugenistas' depararam-se com a necessidade de enfrentar um mesmo enigma: quem são os 'brasileiros'? 'Raça', eugenia, mais enunciados, passaram a ser distintas dimensões temporais a partir das quais a sociedade brasileira poderia ser conhecida. 'Raça', por vezes, foi o termo corrente para aludir-se à história, ao passado e à herança - tudo aquilo que deveria ser esquecido, ter seus males atenuados, corrigidos e redimidos em nome de um futuro eugênico para a nação. Eugenia seria, ao contrário, a concretização redentora de um projeto contemporâneo e moderno, que envolveria os médicos, os educadores e os juristas, irmanados na idealização e transformação de uma nação do futuro. (CUNHA, 2002, p. 242).

Para Olívia Maria Gomes da Cunha, como se vê no fragmento acima, havia, à época, uma distinção entre raça e eugenia, e entende que a última permeou ações de profissionais e de políticas públicas no sentido de 'eugenizar' o país, além do discurso eugênico, ora velado, ora aberto, que perpassava muito da produção científica brasileira, a exemplo de nomes como Raimundo Nina Rodrigues, Renato Kehl, Edgar Roquette-Pinto, entre outros intelectuais, que assumiram, direta ou indiretamente, o eugenismo no Brasil.

Adepta das teorias eugênicas, pró-branqueamento ou miscigenadoras com vistas ao desaparecimento gradual da matriz negra, esta elite branca, do fim do século XIX e das primeiras décadas do século XX, desenvolveu e apresentou estudos antropológicos, entre outras áreas do saber, seja em congressos eugênicos ou em outros espaços, procurando demonstrar, em maior ou menor grau, que a inserção do negro como um cidadão brasileiro seria um problema para o fortalecimento da identidade nacional brasileira.

A Abolição em 1888 e a passagem do Brasil monárquico para republicano em 1889 pressionaram não só as elites intelectuais mas também políticas a rediscutirem a questão racial no país, obrigando-as a enxergar social e politicamente a matriz negra na sociedade, não mais como outrora, por mais de três séculos, na condição de escravo, mas, após a Abolição, na de cidadão.

Neste momento de construção e fortalecimento da República e, em face de um expressivo contingente negro liberto, porém desprovido de políticas públicas com as quais poderia usufruir de sua cidadania, tal grupo foi, intencionalmente ou não, posto à margem da dinâmica social. 
À época do período de intenso tráfico e comércio de escravizados africanos, o negro era visto tão somente como uma mercadoria a ser negociada nos mercados públicos. Contudo, era de se esperar que, com o fim do trabalho escravo, os poderes políticos republicanos construíssem o ideário, não só no discurso mas também na prática, de implementar estratégias de promover igualdade ou um caminho para tal.

Porém, o que se viu foi que a Abolição no papel não fora acompanhada de uma Abolição em ações concretas promotoras de mais igualdade entre cidadãos brancos e ex-escravizados negros. Ter-se-ia assim uma Abolição de direito, mas não uma Abolição de fato.

Na contramão de uma ação política que promovesse inserção dos negros libertos, a imigração de europeus, calcada na ideologia do embranquecimento da sociedade brasileira, pressupunha o fortalecimento da nação e o aprimoramento de sua identidade nacional. Os discursos não se limitaram apenas a estudos e pesquisas acadêmicas em congressos eugênicos, mas se expandiram em áreas diversas, como a política imigratória, materializada na promoção e prática da imigração de europeus para o Brasil. No seu artigo Breve histórico de uma pesquisa psicossocial sobre a questão racial brasileira (2002), ao discorrer sobre as principais questões em torno da pesquisa psicossocial no Brasil, cuja categoria raça se apresentara corrente no debate nacional ou intelectual, Iray Carone afirma:

As políticas imigrantistas do Estado Brasileiro refletiam a preocupação de impedir a "decadência dos brancos” pela vitória dos mestiços através de propostas públicas de favorecimento maciço de imigrantes europeus, considerados superiores aos africanos e asiáticos. (CARONE, 2002, p. 17).

Orquestrada pela elite política brasileira, a imigração de europeus tinha alguns propósitos patentes e definidos: substituir a mão de obra africana e embranquecer a população brasileira, torná-la mais clara, epidermicamente falando, por meio da miscigenação, e assim produzir supostamente, a médio e longo prazo, uma população considerada mais forte, mais apta e mais refinada, culturalmente falando. Estas intenções, circulantes nas últimas décadas do século XIX e nas primeiras do século XX, são recorrentes na obra Canaã, de Graça Aranha, como se pôde constatar em algumas citações deste romance transcritas no presente artigo. Segundo Carone (2002):

A ideologia do branqueamento era, portanto, uma espécie de um darwinismo social que apostava na seleção natural em prol da "purificação étnica", na vitória do elemento branco sobre o negro com a vantagem adicional de produzir, pelo cruzamento inter-racial, um homem ariano plenamente adaptado às condições brasileiras. (CARONE, 2002, p. 16).

À época, o historiador Manuel Bonfim (1868-1932), em seu livro Brasil Nação, editado em 1931, ironiza a inteligência dos políticos 
'Nuvens negras' sob os céus claros e eugênicos na construção identitária da Canaã ou da pátria amada brasil

brasileiros, achando descabida a ideia da imigração europeia como uma medida prática para efetivar as teorias eugênicas e racistas no Brasil pósabolição, sendo a sua uma voz dissonante em meio à política imigratória de então:

No vazio da inteligência, com a grosseria das inspirações, incapazes de correspondência com a realidade, prontos a explorar o que a força e a riqueza material oferecem, os nossos dirigentes são prontos, igualmente em aceitar quantos conceitos juízos thes deem as suas curtas leituras, desde que se acordem à insuficiência de pensamento e grosseria de propósitos que os caracterizam. Assim se explica o empenho com que apelam para a imigração, o valor que lhes dão, as estultices que repetem os interesseiros, falsos e ferozes conceitos, arguidos pela falsa ciência, a serviço do colonialismo, contra os fracos escravizados de ontem, dominados e explorados hoje, em nome de uma pretensa superioridade de raças. (BONFIM, 1996, p. 561).

A leitura de Bonfim (1996) sobre a política imigratória, que é divergente da grande maioria dos pensadores da época, talvez tenha sido uma das causas de ser um dos intérpretes do país esquecidos pela historiografia brasileira. A crítica de Bonfim era pertinente para o período e para a atualidade, quando se observa que a ausência de políticas públicas para esta população negra, na pós-abolição e início republicano, fora uma das principais razões para a manutenção da desigualdade social, pondo em situações diferenciadas brancos e negros, a favor, em geral, do primeiro grupo.

O Espírito Santo foi um dos estados que mais recebeu imigrantes europeus no século XIX, conforme relatam Oliveira (1975) e Rocha (1960). Houve a formação de colônias constituídas a partir da imigração de grupos europeus, sobretudo na região serrana capixaba e em seu entorno, onde atualmente estão os municípios de Santa Leopoldina, Santa Maria de Jetibá, Domingos Martins, Venda Nova do Imigrante, entre outros.

Não é preciso lembrar novamente que Graça Aranha evoca falas de um período em que raça e meio eram elementos cruciais nas discussões sobre o desenvolvimento da nação brasileira. É nesse ponto que reside um dos méritos de Canaã: contracenar, à época, o embate entre favoráveis e contrários ao embranquecimento, por exemplo. Cabe considerar que ainda hoje persistem muitas imagens, crenças e falas arraigadas no tocante à noção de raça, e o que se vê é a atualização do tema, em especial a partir da Constituição Federal de 1988, na qual fica mais explícito o preconceito racial como crime, havendo a necessidade de os indivíduos, não raro, reconstruírem seus discursos, ainda que com as mesmas intenções preconceituosas de outrora. 


\section{Considerações Finais}

A escravidão criou novos cenários políticos, sociais e culturais cujos desdobramentos estão entrelaçados na formação identitária de várias nações, quer isso seja bem visto, aceito ou escamoteado nas historiografias nacionais ou estrangeiras. Não há um caminho de retorno. A diáspora africana e a imigração europeia provocaram significativas mudanças, sem precedentes nas Américas e fora delas.

No Brasil, muito dos pensamentos sobre raça deriva de crenças e posicionamentos calcados em supostas teorias científicas, as quais preconizavam o homem branco como civilizado e central na construção de uma nação desenvolvida, em detrimento do negro e do indígena.

Assim, a sugestiva imagem de um país miscigenado ou plural igualitário, como alguns propalam, formada por várias raças em vivência pacífica, silencia ou tenta silenciar um confronto quanto à necessidade de reconhecimento de um país que se formou - e ainda se forma - alicerçado, em sua prática política e social, sobre concepções de mundo que privilegiaram uma cor de pele como ideal para o desenvolvimento e progresso da nação.

Neste sentido, Canaã é um entre outros romances, escritos por volta das últimas décadas do século XIX e as primeiras do XX, que permite ver o panorama de ideias circulantes entre a passagem do Brasil Império para o Brasil República, momento em que a noção de construção de uma identidade nacional se encontrava em pauta entre elites políticas e intelectuais. As falas dos personagens citadas, entre outras, sintetizam bem que a literatura não esteve ausente deste debate.

No romance, as falas de Lentz sobre os negros, sobre o desenvolvimento ou não do país a partir da categoria raça, problematizam a realidade de um período que insiste em permanecer, seja no imaginário de algumas instituições e pessoas, que ainda veem os negros como ‘nuvens negras' em um céu claro e eugênico, desejoso de resplandecer a pátria amada, Brasil.

\section{Referências}

BOMFIM, Manoel. O Brasil nação: realidade da soberania brasileira. 2. ed. Rio de Janeiro: Topbooks, 1996.

BOSI, Alfredo. História concisa da literatura brasileira. São Paulo: Cultrix, 2006.

CARONE, Iray; BENTO, Maria Aparecida Silva (Orgs.). Psicologia social do racismo. Estudos sobre a branquitude e branqueamento no Brasil. 2. ed. Petrópolis, RJ: Vozes, 2002.

CUNHA, Olívia Maria Gomes. Intenção e gesto. Pessoa, cor e a produção da (in)diferença no Rio de Janeiro, 1927-1942. Rio de Janeiro: Arquivo Nacional, 2002. 
'Nuvens negras' sob os céus claros e eugênicos na construção identitária da Canaã ou da pátria amada brasil

FREYRE, Gilberto. Casa-Grande \& Senzala. 34. ed. Rio de Janeiro: Record, 1988.

HALL, Stuart. A identidade cultural na pós-modernidade. 11. ed. Rio de Janeiro: DP\&A, 2006.

MOUTINHO. Laura. Razão, ‘cor’e desejo. São Paulo: Unesp, 2004.

ORTIZ, Renato. Cultura brasileira e identidade nacional. São Paulo: Brasiliense, 1985. 